\title{
Benefits Assessment for Tactical Runway Configuration Management Tool
}

\author{
Rosa Oseguera-Lohr ${ }^{1}$, Nipa Phojanamongkolkij ${ }^{2}$, Gary Lohr ${ }^{3}$ \\ NASA Langley Research Center, Hampton, VA,23681 \\ and \\ James W. Fenbert ${ }^{4}$ \\ Analytical Mechanics Associates, Inc., Hampton, VA, 23681
}

\begin{abstract}
The Tactical Runway Configuration Management (TRCM) software tool was developed to provide air traffic flow managers and supervisors with recommendations for airport configuration changes and runway usage. The objective for this study is to conduct a benefits assessment at Memphis (MEM), Dallas Fort-Worth (DFW) and New York's John F. Kennedy (JFK) airports using the TRCM tool. Results from simulations using the TRCM-generated runway configuration schedule are compared with results using historical schedules. For the 12 days of data used in this analysis, the transit time (arrival fix to spot on airport movement area for arrivals, or spot to departure fix for departures) for MEM departures is greater $(\mathbf{7 \%})$ than for arrivals (3\%); for JFK, there is a benefit for arrivals (9\%) but not for departures (-2\%); for DFW, arrivals show a slight benefit $(1 \%)$, but this is offset by departures $(-2 \%)$. Departure queue length benefits show fewer aircraft in queue for JFK (29\%) and MEM (11\%), but not for DFW (-13\%). Fuel savings for surface operations at MEM are seen for both arrivals and departures. At JFK there are fuel savings for arrivals, but these are offset by increased fuel use for departures. In this study, no surface fuel benefits resulted for DFW. Results suggest that the TRCM algorithm requires modifications for complex surface traffic operations that can cause taxi delays. For all three airports, the average number of changes in flow direction (runway configuration) recommended by TRCM was many times greater than the historical data; TRCM would need to be adapted to a particular airport's needs, to limit the number of changes to acceptable levels. The results from this analysis indicate the TRCM tool can provide benefits at some high-capacity airports. The magnitude of these benefits depends on many airport-specific factors and would require adaptation of the TRCM tool; a detailed assessment is needed prior to determining suitability for a particular airport.
\end{abstract}

\section{Nomenclature}

ASPM $=$ Aviation System Performance Metrics

CADRS = Combined Arrival/Departure Runway Scheduling

${ }^{1}$ Senior Aerospace Engineer, Aeronautics Systems Analysis Branch, M.S. 442, Hampton, VA Senior Member AIAA.

${ }^{2}$ Operations Research Analyst, Aeronautics Systems Engineering Branch, NASA Langley Research Center, M.S. 238, Hampton, VA.

${ }^{3}$ Senior Aerospace Research Engineer, Crew Systems and Operations Research Branch, NASA Langley Research Center, M.S. 152, Hampton, VA 23681, Senior Member AIAA.

${ }^{4}$ Aerospace Engineer, Analytical Mechanics Associates, Inc., Hampton, VA 23681. 


$\begin{array}{ll}\text { DFW } & =\text { Dallas-Fort Worth International Airport } \\ \text { FAA } & =\text { Federal Aviation Administration } \\ \text { JFK } & =\text { John F. Kennedy International Airport } \\ \text { JPDO } & =\text { Joint Planning and Development Office } \\ \text { MEM } & =\text { Memphis International Airport } \\ \text { MSE } & =\text { Metroplex Simulation Environment } \\ \text { NAS } & =\text { National Airspace System } \\ \text { NextGen } & =\text { Next Generation Air Transportation System } \\ \text { RCM } & =\text { Runway Configuration Management } \\ \text { SORM } & =\text { System-Oriented Runway Management } \\ \text { SRCM } & =\text { Strategic Runway Configuration Management } \\ \text { TRCM } & =\text { Tactical Runway Configuration Management }\end{array}$

\section{Introduction}

The System-Oriented Runway Management (SORM) concept was developed as part of the Airspace Systems Program (ASP) Concepts and Technology Development (CTD) Project, and is composed of two basic capabilities: Runway Configuration Management (RCM), and Combined Arrival/Departure Runway Scheduling (CADRS). RCM is the process of designating active runways, monitoring the active runway configuration for suitability given existing factors, and predicting future configuration changes; CADRS is the process of distributing arrivals and departures across active runways based on local airport and National Airspace System (NAS) goals.

The central component in the SORM concept is a tool for taking into account all the various factors and producing a recommendation for what would be the optimal runway configuration, runway use strategy, and aircraft sequence, considering as many of the relevant factors required in making this type of decision, and user preferences, if feasible. Three separate tools were initially envisioned for this research area, corresponding to the time scale in which they would operate: Strategic RCM (SRCM), with a planning horizon on the order of several hours, Tactical RCM (TRCM), with a planning horizon on the order of 90 minutes, and CADRS, with a planning horizon on the order of 15-30 minutes ${ }^{1}$. Algorithm development was initiated in all three of these areas, but the most fullydeveloped to date is the TRCM algorithm.

Earlier studies took a high-level approach to benefits, estimating aggregate benefits across most of the major airports in the National Airspace Systems (NAS), for both RCM and CADRS ${ }^{2}$. Other studies estimated the benefit of RCM and CADRS using various methods of re-sequencing arrivals to reduce delays ${ }^{3,4}$, or better balancing of arrival fixes $^{5,6}$. Additional studies looked at different methods for performing the optimization involved in selecting the best Runway Configuration Plan (RCP) to use ${ }^{7-10}$.

Most of these previous studies were high-level or generic in nature (not focusing on specific airports), and benefits were aggregated for the entire NAS, with relatively low fidelity simulation of SORM functions and aircraft trajectories. For SORM research, a more detailed benefits assessment of RCM and CADRS for specific airports or metroplexes is needed.

The objective for this study is to conduct an assessment using metrics related to benefit mechanisms, through simulations conducted with and without TRCM at specific airports, using the TRCM tool and specific airport adaptations. The objective function of the TRCM tool seeks to minimize transit time, i.e. the amount of time required for a flight to transit from the arrival fix to the "spot" (location on the airport surface where control is transferred from ground controllers to ramp controllers) for arrivals; for departures the transit time is from the spot to the departure fix. The TRCM algorithm looks for the airport configuration that results in the shortest transit time for all flights in a particular time interval, thus transit time is the primary metric for the benefits assessment. Benefits were assessed using current-day (2009-2010) demand levels only; future demand levels will be assessed separately.

\section{Benefit mechanisms and metrics}

Benefits that may be attributed to TRCM use include:

- Increased capacity due to better selection of configuration, runway use, and timing of configuration change

- More efficient ground and airborne operations due to better balancing of arrivals/departures among runways and fixes (increased throughput)

- Reduced delays due to reduced time in departure queues, more efficient route through TRACON airspace 
These benefits would apply to the NAS level as well as for the individual aircraft or operator. For the airport operator, benefits result from being able to maintain a more predictable schedule, increased throughput (more flights per day, more passengers per day), and fewer delays. At the metroplex (or regional level), as well as at the NAS level, it is anticipated that benefits would be similar to those at the individual airport level. For this study, only benefits at a single airport are investigated.

To assess these benefits, the effect of the TRCM tool on other metrics can be measured, by comparing timing of flights achieved through conventional means (using historical data) versus what is achieved when using runway configuration plans from the TRCM tool. This could be measured as the amount of time it takes for a flight to transit a given amount of airspace (the transit time), and leads to other metrics such as delays and fuel used. In addition, other metrics such as queue length and amount of airborne transit time vs transit time on the surface can be compared. It is important to note that, because the benefit is considered at the system level (i.e., not for individual flights), some flights might sustain a greater delay with the TRCM-generated schedule, if it results in a net benefit for the airport as a whole.

\section{Method of test}

The test method consists of comparing results from simulations using the TRCM-generated runway configuration schedule, versus a baseline case; the baseline case consists of results from simulations using the historical runway configuration schedule. The historical information was obtained using the Federal Aviation Administration's (FAA) Aviation System Performance Metrics (ASPM) online access system, accessible through the FAA's Operations and Performance Data website ${ }^{11}$. The same demand data were used for both the baseline and TRCM cases; this set of data consisted of twelve days of historical data from each of the airports studied. Further details of the TRCM tool, simulation environment, and demand data are included in this section.

The software used for simulation included the single-airport TRCM and the Metroplex Simulation Environment (MSE), both of which were developed by Mosaic ATM under contract to NASA [Contract \# NNL09AA02B]. The two parts of the software are described below.

\section{A. Tactical Runway Configuration Management Tool}

The TRCM tool was developed by Mosaic ATM, as part of the suite of tools for SORM. It takes as input a set of flights for a period of time (currently 90 minutes), including flight and weather information, and produces a plan for a recommended runway configuration plan to use for a given time interval (currently 15 minutes), based on the given conditions. The TRCM software runs entirely within the MSE, which provides feedback on updated flight trajectories for the planning cycle, and then simulates the airborne and ground trajectories for individual aircraft after the runway configuration has been determined.

The tool is designed to produce a runway configuration that results in lower overall transit times for a given airport and time period; as such, the primary metrics for this study will measure differences in transit time when using TRCM vs the non-TRCM case. Other primary metrics include fuel usage and departure queue length. It is anticipated that the magnitude of these benefits is proportional to the traffic demand level for the particular airport.

\section{B. Metroplex Simulation Environment}

The TRCM tool runs within the Metroplex Simulation Environment (MSE), a self-contained platform for conducting fast-time simulation of many flights into a given airspace. For this study, the airspace consists of a particular airport environment, including the surface operations and flight between the runway and a given airborne fix. For arrivals, the fix is one of three or four waypoints used as part of the arrival route for arriving flights; for departures, there are numerous fixes that can be used, depending on the direction of flight following departure. The three airport environments used for this study are Memphis International Airport (MEM), John F. Kennedy International Airport (JFK), and Dallas-Ft. Worth International Airport (DFW). MEM was selected to provide the SORM research team with data for comparison with their upcoming field evaluation of TRCM; JFK was used because it had previously been identified as the primary airport of interest for SORM studies; DFW was chosen due to its higher traffic volume and more complex ground operations.

MEM has three parallel runways in a North/South orientation (18R/36L, 18C/36C, and 18L/36R) and one East/West runway $(9 / 27)$ on the north side of the airport. DFW has five parallel runways in a North/South orientation (18R/36L, 18L/36R, 17R/35L, 17C/35C, and 17L/35R), and two parallel runways in a Northwest/Southeast orientation (13R/31L and 13L/31R). JFK has two sets of parallel runways, one set in a Northwest/Southeast orientation $(13 \mathrm{R} / 31 \mathrm{~L}$ and $13 \mathrm{~L} / 31 \mathrm{R})$, and the other in a Northeast/Southwest orientation (4L/22R and 4R/22L). Runway configurations evaluated in this study were based on the most frequently used, based 
on historical data from ASPM. For this study, there were four different (unique) combinations of runway usage identified for inclusion in the evaluation for MEM, 10 combinations at DFW, and 20 combinations at JFK. Note that this does not represent all the possible combinations in which the runways could be used at each of these facilities, however they represent the most commonly used at these facilities.

\section{Demand Data}

A range of conditions for test runs is needed in order to cover some of the primary factors that could affect the resulting benefits. The demand data used for this study comprised a set of historical data that covers the period of Fiscal Year 2010 (October 1, 2009 through September 30, 2010), which was adopted and recommended by the Joint Planning and Development Office (JPDO) for NextGen research. These days were identified by the FAA as capturing trends in seasonal variations in aviation performance in the NAS for that year, using a method developed to minimize differences in predicted and actual levels of desired performance metrics at the daily level ${ }^{12}$. Simulation runs conducted using historical configurations are considered the Baseline cases, and those using the TRCMgenerated configurations are called TRCM runs; for each data file (each day), results from the TRCM run were compared with the corresponding Baseline case to assess the benefits.

The set of days from which the data were obtained are listed in Table 1, along with the number of operations that took place at each of the three airports. Note that the number of operations is less than what would be obtained from a query of ASPM, because the full set of operations is pared down to remove flights that are not relevant (such as general aviation flights), and other flights with invalid data, and to adjust for different time zones in order to obtain a 24-hour sample. However, the resulting demand data, although less than the full ASPM number, still reflects the relative levels of demand - i.e., which days had higher demand than others.

Table 1. Dates for historical data used for analysis.

\begin{tabular}{|c|l|l|l|l|l|}
\hline $\begin{array}{c}\text { Index } \\
\text { Number }\end{array}$ & Date & Week Day & $\begin{array}{l}\text { MEM } \\
\text { operations }\end{array}$ & $\begin{array}{l}\text { JFK } \\
\text { operations }\end{array}$ & $\begin{array}{l}\text { DFW } \\
\text { operations }\end{array}$ \\
\hline 1 & $10 / 6 / 2009$ & Tuesday & 981 & 845 & 1593 \\
\hline 2 & $10 / 17 / 2009$ & Saturday & 621 & 919 & 1525 \\
\hline 3 & $11 / 20 / 2009$ & Friday & 995 & 1039 & 1779 \\
\hline 4 & $1 / 10 / 2010$ & Sunday & 653 & 930 & 1708 \\
\hline 5 & $3 / 9 / 2010$ & Tuesday & 1006 & 977 & 1772 \\
\hline 6 & $3 / 25 / 2010$ & Thursday & 1050 & 1032 & 1778 \\
\hline 7 & $5 / 6 / 2010$ & Thursday & 1050 & 968 & 1813 \\
\hline 8 & $5 / 18 / 2010$ & Tuesday & 1044 & 950 & 1810 \\
\hline 9 & $6 / 5 / 2010$ & Saturday & 645 & 960 & 1578 \\
\hline 10 & $7 / 3 / 2010$ & Saturday & 695 & 1046 & 1584 \\
\hline 11 & $7 / 13 / 2010$ & Tuesday & 1059 & 975 & 1819 \\
\hline 12 & $7 / 22 / 2010$ & Thursday & 1067 & 1093 & 1854 \\
\hline
\end{tabular}

For the twelve sample days used, the day with the highest demand level was July 22, 2010 for all three airports; the day with the lowest demand level was October 17, 2009 for both MEM and DFW, but for JFK it was October 6, 2009. The ratio of low to high demand varied greatly for the three airports; for JFK, demand on the lowest day was $77 \%$ of demand on the highest day; for DFW the lowest day was $82 \%$ of the highest; for MEM the lowest was 58\% of the highest. The large variation in demand levels for MEM can be attributed to the fact that FedEx is the largest airline operating at MEM, sometimes comprising over $40 \%$ of the day's traffic; on days when there are not many FedEx flights (usually Friday and Saturday nights), the volume of traffic drops dramatically. For the days that follow (Saturday and Sunday), demand was often under $65 \%$ of the maximum value. This unique profile of traffic demand can have a significant effect on benefits.

Historic traffic demand for the entire year obtained from ASPM also showed very different profiles for the three airports: a plot of daily demand for MEM for the entire year would show two bands of traffic levels, centered around 800 and 1100 operations per day; the lower demand days were those without FedEx flights, the higher level was the days when FedEx had an overnight and mid-afternoon operations. At JFK for the year traffic was generally in the range of 1000-2000 operations per day, with most days between 1000-1500 operations, and an observable seasonal variation (lower in winter months, higher in summer months). DFW demand was more consistent, with demand levels between $1500-2000$ operations for $85 \%$ of the days (the remainder were scattered on the higher side).

4

American Institute of Aeronautics and Astronautics 


\section{Results}

\section{A. Transit Time}

Fig. 1 shows the difference in average transit times for all arrivals and departures, for all days at the three airports. The darker-hued bar in each pair is the arrival transit time, the lighter-hued bar is the departure transit time. The differences were computed as Baseline minus TRCM, thus a bar above the zero line represents a benefit; bars that extend below the zero-line indicate a negative benefit, or offset.

Upon inspection, it can be seen that most of the blue bars (MEM) are above the zero-line, indicating a positive benefit for MEM; for many days this benefit was substantially over one minute, especially for the departures (lightblue). The average transit time benefit for MEM for these twelve days was 47s for arrivals and 98s for departures.

For JFK (brown bars), the arrivals were also substantially above zero for most of the days (average of 149s); however the departures (in light brown) were distributed both above and below, with a net negative (-24s) for the twelve days. This would indicate that minimizing the transit time for arrivals was given priority over minimizing transit time for departures.

For DFW (green bars), the results were somewhat less clear. Although for most of the days the arrivals showed a positive benefit (average for arrivals was 17s), as in the JFK case the average for departures was negative (-18s), also indicating a priority for arrivals over departures. However, the net average (combining arrivals and departures) over the twelve days was just slightly negative for DFW, whereas it was positive for both MEM and JFK.

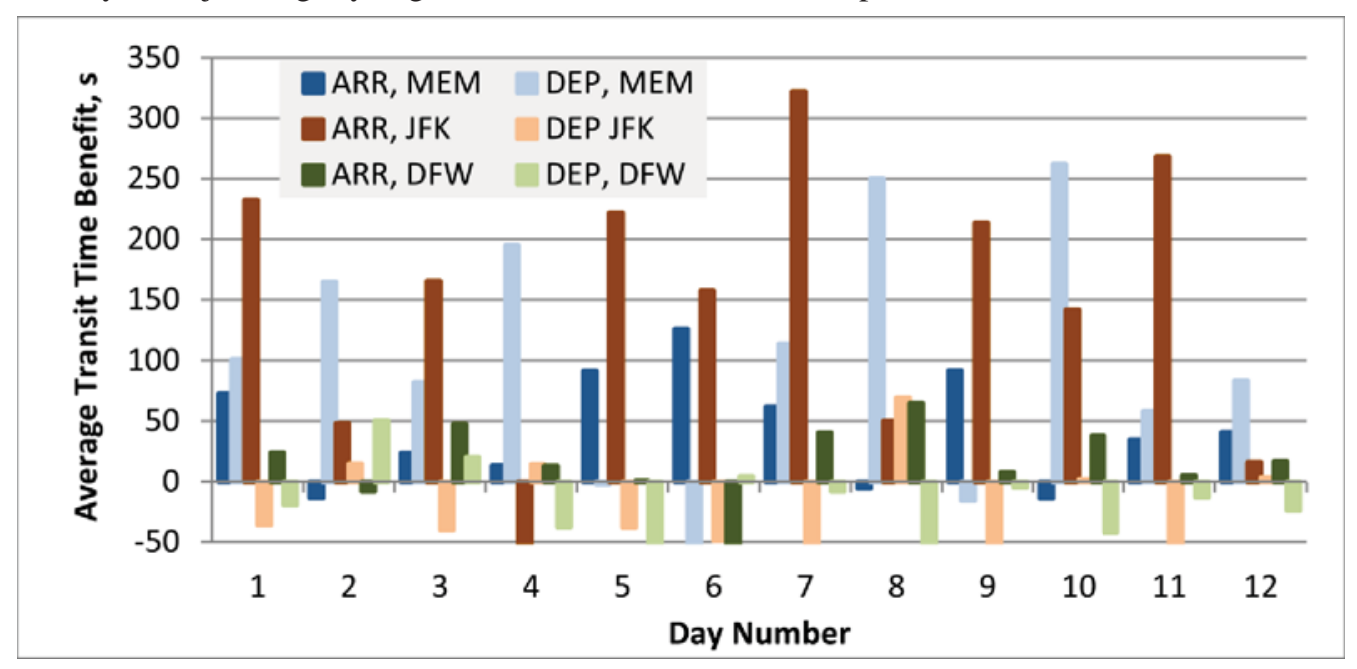

Figure 1. Transit time benefit (Baseline-TRCM), arrivals and departures, all airports and days.

When averaged over all 12 days, the transit time benefits are substantial for MEM and JFK, but mixed for DFW, as shown in Table 2. For MEM, departures the benefit was almost two and a half times that for arrivals - this is most likely due to the shortened taxi time required for aircraft that are located at the north end of the runways (primarily FedEx), when the flow direction is changed to South Flow. It is important to note that the baseline for this is from historic data, which may not be entirely accurate with regards to what configuration was actually used, especially for short periods of time during the night. Subject matter experts that were consulted on this question indicated that, most likely the flow direction would have been changed more often than what was reflected in the ASPM database. Thus, it is likely that the flow direction was changed (winds and other factors allowing), but the change was not reflected in the ASPM database; this would mean that the Baseline case would have many more flights with shorter taxi times than what was simulated, and computed transit time benefits would be much lower than what is shown in the table.

Table 2. Average reduction in mean transit time (baseline minus TRCM) overall all days.

\begin{tabular}{|l|l|l|}
\hline Airport & Arrivals & Departures \\
\hline MEM & $43.6(3 \%)$ & $103.1(7 \%)$ \\
\hline JFK & $148.5(9 \%)$ & $-23.4(-2 \%)$ \\
\hline DFW & $16.6(1 \%)$ & $-18.4(-2 \%)$ \\
\hline
\end{tabular}

For JFK, the transit time benefit is much greater for 
arrivals than departures; this would indicate that arriving flights were given priority over departures. It is possible that this came about because for arrivals, the in-flight time consitutes a greater proportion of the overall transit time than the airport movement area (AMA) time, so minimizing the transit time would be of greater benefit to arrivals than to departures; most likely this would be the case at most airports. At MEM, the high concentration of FedEx flights affects not only the magnitude of the benefit, but also where the benefit is realized - in the case of FedEx, a shorter taxi time would result in a much greater overall benefit for departures, due to the large volume of flights that would be affected.

At DFW, the mixed results indicate that perhaps the TRCM algorithm requires modification to accommodate the more complex traffic situation at DFW. In particular, the runway layout and terminal locations require aircraft to cross runways during their ground movements. Although the computed transit time includes surface operations and the objective function of the TRCM algorithm seeks to minimize transit time, it is possible that the time required for surface operations is not adequately taken into account during the planning phase of the TRCM tool, in particular the time required to wait when crossing an active runway. A way of correcting this could be by adding a penalty to the transit time estimate used in the planning phase when crossing an active runway is required, such that it would make a change in flow direction less attractive if it would increase the number of runway crossings.

To better understand what contributed to some of these differences, the transit times were further broken down to examine the airborne and surface contributions. Fig. 2 shows the transit time benefits for each of the three airports, broken down to flight and taxi segments.

The figure shows that there were benefits on both the surface and airborne segments for both arrivals and departures at MEM (blue bars), with the greatest contribution from taxi time for departures. For JFK (red bar), the largest contribution came from flight time for arrivals, and the substantial deduction from departure taxi operations more than offset the benefit for arrival taxi operations. For DFW (gray bars), the only benefit was for arrivals during their flight time, and a neglible amount for departures during flight; the taxi part of the operations showed negative results for both arrivals and departures, which offset the overall arrival time benefit.

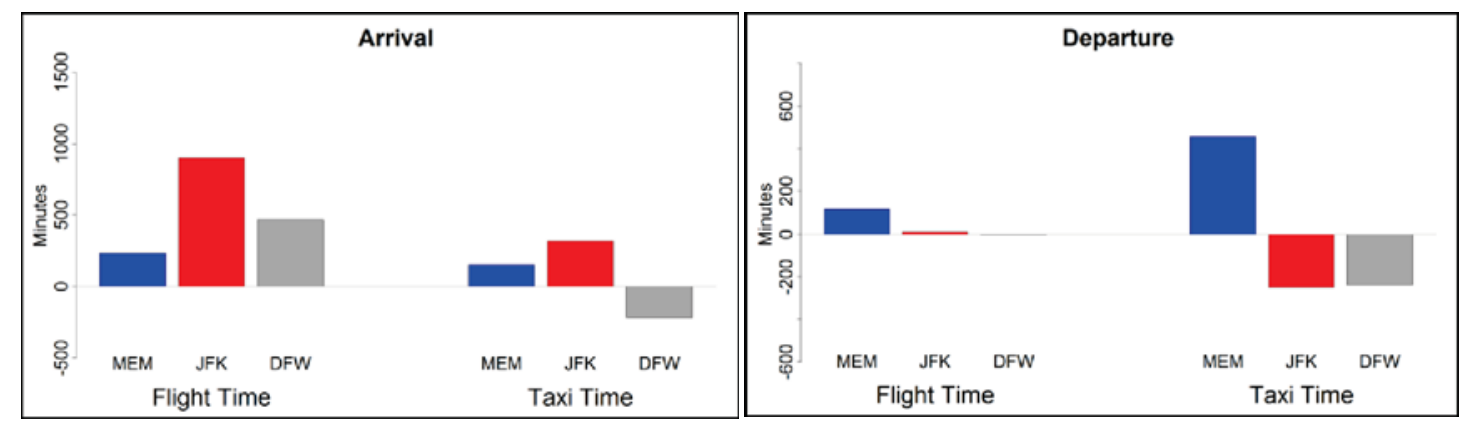

Figure 2. Flight and surface transit time benefit contributions for MEM, JFK, and DFW.

\section{B. Departure Queues}

One of the parameters recorded for each flight is the number of aircraft ahead in the queue, when the aircraft approaches the runway for departure. Fig. 3 shows resulting number of occurences for number of aircraft in queue, for each of the three airports; each chart shows six bars: the two blue bars are the means for all twelve days, for TRCM and Baseline cases; the green bars are the means only for the four days with the lowest demand levels, TRCM and Baseline cases; the orange bars show the means only for the four days with the highest demand levels, TRCM and Baseline cases. Note that the days with lowest and highest demand levels were different for each of the four airports. From the figures, it can be seen that, for MEM and JFK, in most cases the TRCM tool provided a benefit of fewer aircraft in the departure queue (the TRCM bar is lower than the corresponding Baseline bar). Also, the highest number of aircraft in queue for TRCM was higher, particularly for JFK where the highest number of aircraft in queue was 5 in the TRCM cases, compared to 7 in the Baseline cases. 


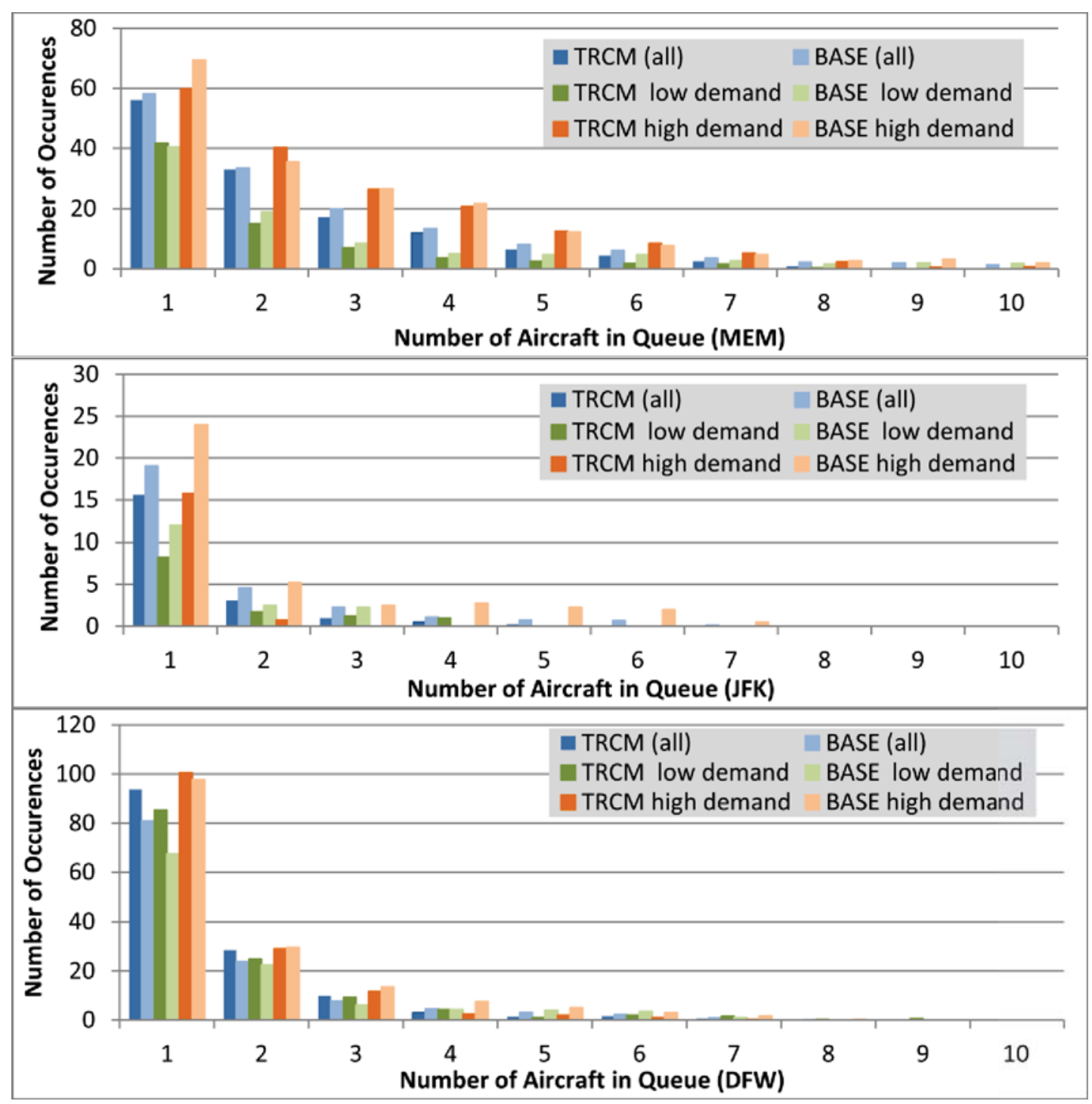

Figure 3. Mean aircraft in queue at the three airports for all test days.

Table 3 shows departure queue results in percent savings for the different situations (all twelve test days, four lowest demand days only, and four highest demand days only). For MEM and DFW, all cases showed benefit. For JFK there was not an appreciable difference in percent benefit whether or not all days were used, although the total number of aircraft in queue was higher on highdemand days and lower on low-demand days, as can be seen in the bar chart. This could be partially because the difference in number of operations on high- and lowdemand days was not as great for JFK, and it usually operates close to its capacity limit. For MEM, there was a noticeable difference in percent of benefit, with the lowest four days seemed to generate the most benefit (19.1\%), the highest four had the lowest benefit (5\%), and the benefit for the full set of days fell in between (10.6\%); most likely this is due to the larger differences in number of operations between low- and high-demand days. For DFW, the results were very different, with no benefit for the full set or lowest four days, and a small benefit for the highest four days. The lack of any departure queue benefits at DFW could indicate that the TRCM algorithm needs to be Table 3. Percent benefit in departure queue length for all airports.

\begin{tabular}{|l|l|l|l|}
\hline & MEM & JFK & DFW \\
\hline TRCM & 1592 & 245 & 1668 \\
\hline BASE & 1780 & 343 & 1480 \\
\hline All days & $10.6 \%$ & $28.6 \%$ & $-12.7 \%$ \\
\hline TRCM & 293 & 83 & 516 \\
\hline BASE & 362 & 113 & 435 \\
\hline Lowest 4 & $19.1 \%$ & $26.5 \%$ & $-18.6 \%$ \\
\hline TRCM & 707 & 98 & 588 \\
\hline BASE & 744 & 137 & 634 \\
\hline Highest 4 & $5.0 \%$ & $28.5 \%$ & $7.3 \%$ \\
\hline
\end{tabular}




\section{Fuel Burn (Surface)}

Fuel use data were only available for surface operations, and is summarized in Fig. 4 for all three airports, for the twelve days. The fuel use data is divided into three different segments: ramp, airport movement area (AMA), and runway, and is shown separately for arrivals and departures. As can be seen, the fuel used on the movement area (dark blue bars for departures and light blue bars for arrivals) dominates that from the other segments for all three airports. In the case of MEM, most days showed a benefit in fuel use on the movement area for both arrivals and departures (most of the bars extend far above zero); for JFK, there was a benefit for arrivals, but most departures

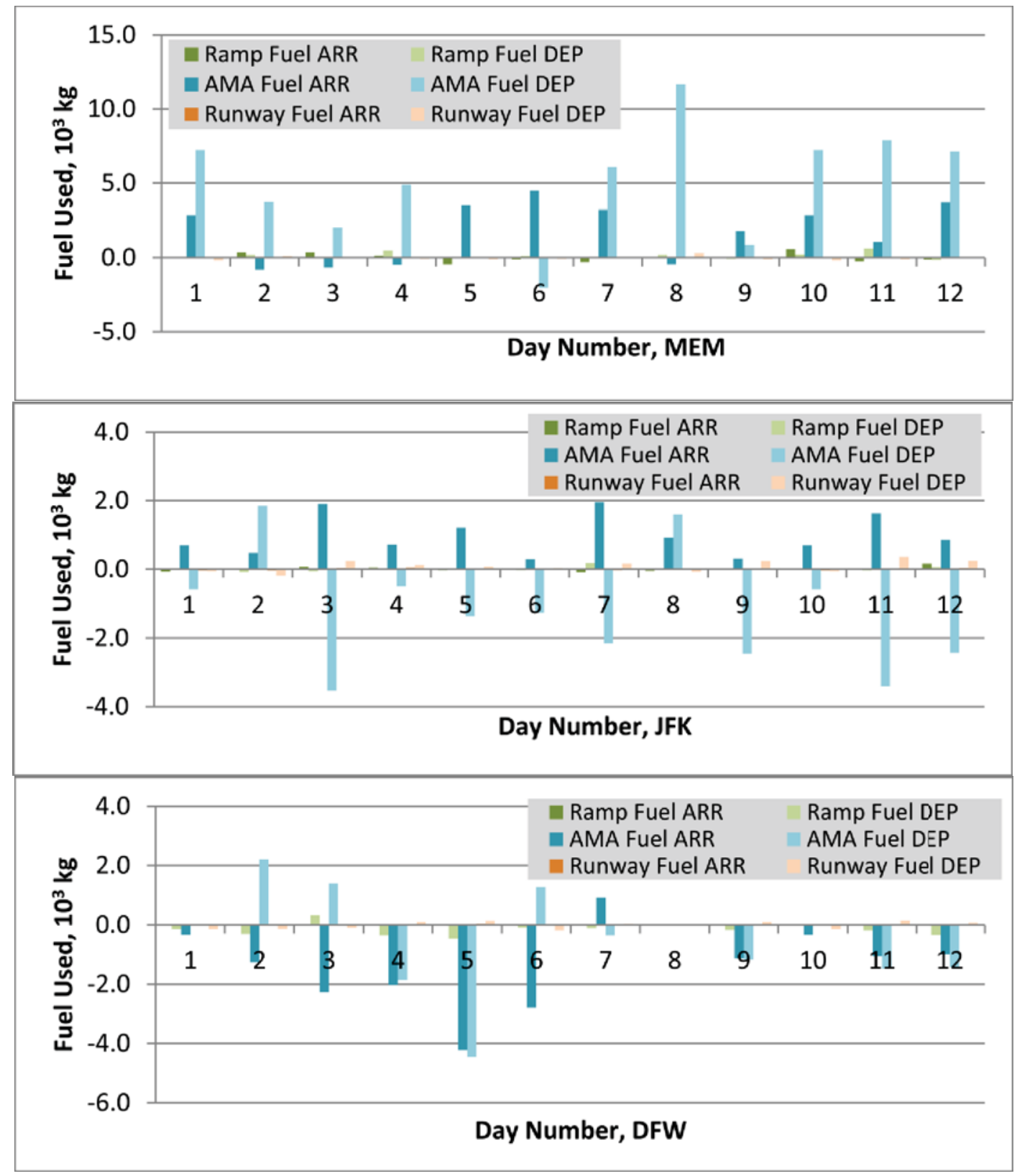

Figure 4. Fuel use for surface operations, by segment.

showed increased fuel usage. For DFW, very little change was seen for most days, but with large negative fuel burn differences (more fuel was used) for several days for both arrivals and departures. The percent average fuel differences over all twelve days is summarized in Table 4. It is also noteworthy that for most days, the vast majority of arrivals had no difference in fuel use for Baseline versus TRCM runs (see Table 5). For departures, half or more

8

American Institute of Aeronautics and Astronautics 
of the operations had no difference in fuel use for Baseline versus TRCM. Thus, the benefits or offsets seen in the results are for at most, half of the total daily operations.

Further subdividing the fuel use in the AMA segment by different phases of taxiing (stopped, accelerating, and steady taxiing) showed that the time spent in "stopped" mode had a very large negative value for DFW, much more than either of the other two phases; this was not true at the other two airports, which had little or no fuel benefit loss when stopped. This would suggest that the resulting negative values seen for transit time benefits at DFW may be largely due to the time lost during surface operations, possibly while waiting for runway crossings. Possible ways to alleviate this effect could be to impose a time penalty when the taxi path requires crossing an active runway, or possibly to limit the number of active runway crossings for each flight; the feasibility of either of these approaches in reducing surface losses would need to be examined further prior to drawing definitive conclusions about the effectiveness of TRCM at DFW.

Table 4. Percent average difference in fuel use over all twelve data days.

\begin{tabular}{|l|r|r|r|r|r|r|}
\cline { 2 - 8 } \multicolumn{1}{c|}{} & \multicolumn{1}{l|}{$\begin{array}{l}\text { Ramp } \\
\text { (A) }\end{array}$} & \multicolumn{1}{l|}{$\begin{array}{l}\text { Ramp } \\
\text { (D) }\end{array}$} & \multicolumn{1}{l|}{$\begin{array}{l}\text { AMA } \\
\text { (A) }\end{array}$} & \multicolumn{1}{l|}{$\begin{array}{l}\text { AMA } \\
\text { (D) }\end{array}$} & \multicolumn{1}{l|}{$\begin{array}{l}\text { Runway } \\
\text { (A) }\end{array}$} & \multicolumn{2}{l}{$\begin{array}{l}\text { Runway } \\
\text { (D) }\end{array}$} \\
\hline MEM & 0.34 & 0.69 & 11.78 & 43.77 & -4.48 & -1.05 \\
\hline JFK & -0.01 & -0.01 & 7.14 & -8.69 & -2.69 & 2.00 \\
\hline DFW & -0.08 & -0.63 & -5.06 & -2.38 & 2.55 & -0.16 \\
\hline
\end{tabular}

Table 5. Percent of operations with fuel differences (Baseline - TRCM), AMA segment only.

\begin{tabular}{|r|r|r|r|r|r|r|}
\cline { 2 - 7 } \multicolumn{1}{c|}{} & \multicolumn{2}{|c|}{ MEM } & \multicolumn{2}{c|}{ JFK } & \multicolumn{2}{c|}{ DFW } \\
\cline { 2 - 7 } \multicolumn{1}{c|}{} & ARR & DEP & ARR & DEP & ARR & DEP \\
\hline No difference & 71 & 49 & 94 & 49 & 91 & 70 \\
\hline positive & 13 & 29 & 3 & 25 & 5 & 12 \\
\hline negative & 16 & 21 & 3 & 27 & 4 & 18 \\
\hline
\end{tabular}

\section{Airport Configuration Changes}

Although the authors did not attempt to measure the workload associated with configuration changes, it is known that changes in runway configuration is accompanied by increased workload for controllers and managers. As a way of judging whether or not the workload might be increased with use of the TRCM tool, a comparison can be made of the number of changes recommended by the TRCM tool, and the historical number of changes that occurred on those days. Generally speaking, a change in direction of flow (for example, from North Flow to South Flow at an airport that has North-South runways) can result in a loss of efficiency, increase in workload for controllers, and additional coordination required between the airport and TRACON management, as the flow of traffic in the terminal must change. Changes in the way runways are used (for arrival, departure, or both) without a change in flow direction does not have as high a cost, in terms of efficiency and workload. For this study, the number of configuration changes per day were computed, and subdivided by the type of change. Three types of changes were counted: 1) change in flow direction; 2) change in arrival runway (making an additional runway available for arrivals, or removing it from use as an arrival runway); and 3) change in departure runway (making an additional runway available for use as a departure runway, or removing it from use as a departure runway). The latter two categories include changing runways to mixed use.

The first of these categories, a change in flow direction, affects arrivals more than departures. Because of the way arrivals are routed into terminal areas, there must be enough airspace to allow published routes to be flown through the TRACON airspace and proper airport traffic patterns to be flown, including any additional vectoring or path-stretching that might be needed for spacing considerations. A change in flow direction must account for all this, especially for any flights that would have to be re-routed in order to accommodate the new runway configuration. 
Because arrivals are affected more by change in flow direction, the changes to flow direction that were counted for this study were those that were associated with a change in the primary arrival runways used.

For the other two categories, changes in an arrival (or departure) runway can mean that a runway that was being used for arrivals (or departures) only is changed to allow both types of operations (mixed-use), or a mixed-use runway is changed to arrivals only (or departures only). Fig. 5 shows the number of changes in flow direction, arrival runway usage, and departure runway usage that occurred on the selected days for MEM, JFK, and DFW.
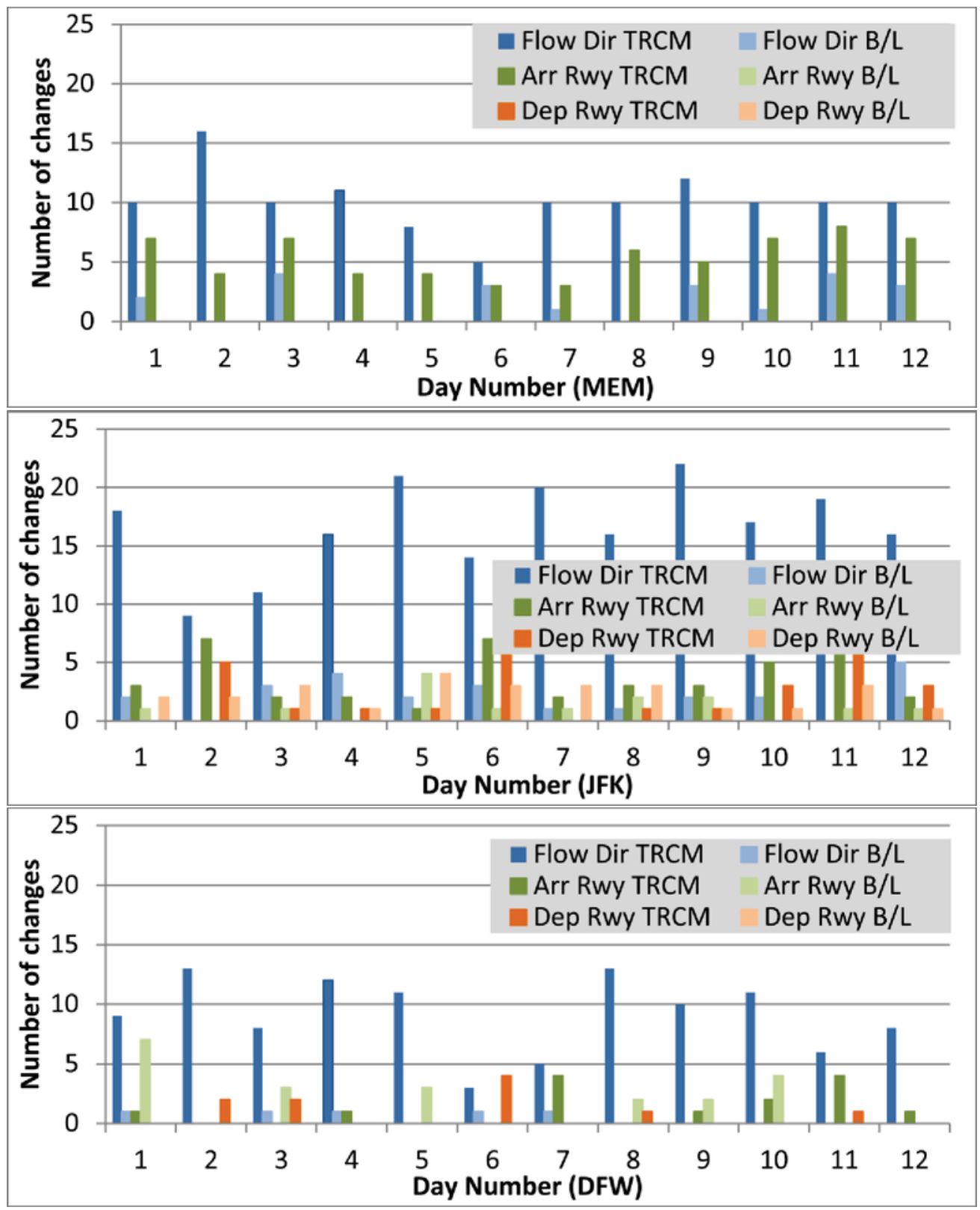

Figure 5. Number of configuration changes for each day, MEM, JFK, and DFW.

\section{Changes in Flow Direction}

As can be seen, the number of flow direction changes recommended by TRCM was several times more than what was historically used at all three airports (blue bars). The number of changes in how arrival or departure 
runways were used (green and orange bars, respectively) were, in most cases, less than the number of flow direction changes for the three airports.

The mean number of changes in flow direction across all days are shown for the three airports in Table 6. For all three airports, the average number of changes in flow direction recommended by TRCM were several times greater than the historical data would suggest. The average number of changes recommended for MEM was almost 6 times the historical case; for JFK it was 7.5 times, and for DFW more than 20 times the historical average. These values are clearly excessive compared to what is normally found at airports throughout the NAS. Although a benefit of having TRCM is the ability to better manage the changes in runway configuration, at some point the changes in flow direction could be excessive, primarily from the standpoint of controller workload. The authors are not aware of literature that defines what would be the number of changes in flow direction at an airport that would be either optimal, too few, or too many, so it is not possible to place a value on these numbers. However, considering that there are generally 16 hours of the day when the majority of traffic operations occur at most airports, having 16 configuration changes would mean an average of one per hour. The TRCM algorithm was limited to changing configurations not more than once every 45 minutes, however there was not a limit on how many changes per day were allowed, so clearly more investigation of this issue needs to be done. It is likely that the TRCM tool would need to be adjusted to a particular airport's needs, to limit the number of changes per day to what would be considered acceptable.

Table 6. Mean and standard deviation for changes in flow direction for MEM, JFK, and DFW.

\begin{tabular}{|l|l|l|l|l|l|l|}
\hline \multirow{2}{*}{} & \multicolumn{2}{|c|}{ MEM } & \multicolumn{2}{c|}{ JFK } & \multicolumn{2}{c|}{ DFW } \\
\cline { 2 - 7 } & Mean & $\begin{array}{l}\text { Std. } \\
\text { Dev }\end{array}$ & Mean & $\begin{array}{l}\text { Std. } \\
\text { Dev }\end{array}$ & Mean & Std. Dev \\
\hline Baseline & 1.8 & 1.6 & 2.1 & 1.5 & 0.4 & 0.5 \\
\hline TRCM & 10.2 & 2.5 & 16.6 & 3.9 & 9.1 & 3.2 \\
\hline
\end{tabular}

\section{Changes in runway usage}

For all the airports, the number of runway usage changes was much smaller than the number of changes in flow direction. Also, most of the runway usage changes that were implemented were for arrival runways, with fewer for departure runways. At MEM, the runway usage changes were not reported in the Baseline results, due to the way in which the runway configurations were defined in the TRCM code. For MEM, only four configurations were defined: North and South flows, with each having an option for Static or Dynamic Arrivals. This option allowed arrivals to be assigned to runways that were being used for departures, as a means of off-loading some of the arrivals for reduction of delays. Since no option was included for Static or Dynamic Departures, there were no runway usage changes reflected in the resulting configuration schedule output.

\section{Conclusion}

The benefits that were explored in this analysis were lower transit time for arrivals, shorter departure queues, and lower fuel burn for arrivals and departures. Based on results from this analysis, TRCM provided transit time benefits for arrivals at all three airports (3\%, 9\%, and 1\% for MEM, JFK, and DFW, respectively), and for departures at MEM (7\%), when averaged over all flights. Benefits in departure queue length (ranging from 5-29\%) and fuel use (ranging up to 44\%) were also noted. The magnitude of these benefits depends on many factors. One of these factors is the number and type of options available for runway configuration and usage. Another factor that can affect the magnitude of benefits is the traffic demand on a particular airport; although this factor was not included in the current study, it is planned as part of the follow-on study to this effort. If an airport routinely operates near its capacity limit, more timely changes in flow direction can minimize the impact of the configuration change. Also, allowing use of runways for mixed use, or opening additional runways for use during short periods of time when demand increases can help reduce departure queues and allow the airport to absorb short periods of increased demand. Both of these functions can be facilitated by use of the TRCM tool.

A higher fidelity assessment of benefits is recommended prior to determining suitability of TRCM at any particular airport. This would include more accurate recording of historical configurations used, to ensure a fair 
baseline condition for comparison. Also, a carefully modeled adaptation to include all configurations and runway use plans that could help improve traffic flow is recommended.

In this study, results show greater benefits in transit time, fuel use, and departure queue length at MEM than at JFK; results from DFW have not shown any significant benefit, and often have shown a net negative effect. It is believed that this is due to excessive taxi times, which in turn may be caused by delays due to runway crossings. If this is the case, this problem may be resolved by modification of the TRCM algorithm to include a time penalty for runway crossings. It is also possible that the greater number of runway changes recommended by TRCM results from minimization of transit times for arriving flights, which translates to shorter airborne time for these flights at the expense of the departures and ground operations. The objective function for determining whether or not a runway change is warranted needs to be explored more closely; possible changes could include reducing the number of changes per day (results showed this to be substantially higher than historic data, especially at DFW), including surface time as part of the objective function, or better estimating the time required for surface operations. Conducting this study with a different simulation environment would also help to verify results obtained.

Follow-on studies to this analysis should include further investigation of sensitivity of benefits to demand levels and number of configuration changes allowed, and possible modifications to the TRCM algorithm to better account for surface operations. Assessment of benefits at additional airports would also be useful in characterizing TRCM benefits and allow extrapolation to estimate NAS-wide benefits.

\section{Acknowledgment}

The authors gratefully acknowledge the contributions of Steven Robbins and Randall Van Valkenburg.

\section{References}

${ }^{1}$ Lohr, G. W., Brown, S., Stough, H. P., Atkins, S., Eisenhawer, S., and Long, D., "System Oriented Runway Management: A Research Update," Ninth USA/Europe Air Traffic Management Research and Development Seminar, Berlin, Germany, June 2011

${ }^{2}$ Lohr, G., Brown, S. Atkins, S. Eisenhawer, S., Bott, T., Long, D., and Hasan, S., "Progress Toward Future Runway Management," Eleventh AIAA Aviation, Technology, Integration, and Operations (ATIO) Conference, AIAA-2011-6925, Virginia Beach, VA, September 2011

${ }^{3}$ Zhang, R. and Kincaid, R., "Robust Optimization Model for Runway Configurations Management," Eleventh AIAA Aviation, Technology, Integration, and Operations (ATIO) Conference, AIAA-2011-6922, Virginia Beach, VA, September 2011

${ }^{4}$ Vaddi, S., Tandale, M., and Cheng, V., "Robustness Analysis of Terminal Area Scheduling Operations Using a Queuing Framework," AIAA Guidance Navigation, and Control Conference, AIAA 2011-6532, Portland, OR, August 2011.

${ }^{5}$ Tandale, M., Vaddi, S., Wiraatmadja, S., and Cheng, V. "A Queuing Framework for Terminal Area Operations," AIAA Guidance Navigation, and Control Conference, AIAA 2011-6363, Portland, OR, August 2011.

${ }^{6}$ Chen, H., Zhao, Y., and Provan, C., "Multiple-Point Integrated Scheduling of Terminal Traffic,” Journal of Aircraft, Vol. 48, 2011, No. 5, pp. 1646-1657.

${ }^{7}$ Chen, H., Zhao, Y., and Provan, C., "Dynamic Real-time Scheduling of Terminal Traffic," AIAA Guidance Navigation, and Control Conference, AIAA 2011-6364, Portland, OR, August 2011.

${ }^{8}$ Vinay, V. and Delaurentis, D., "A Metroplex Capacity Enhancement Strategy Through Coordinated Use of Runway Dependencies,“ Eleventh AIAA Aviation, Technology, Integration, and Operations (ATIO) Conference, Virginia Beach, VA, September 2011

${ }^{9}$ Schleicher, D., Clarke, J.P., Saraf, A., and Timar, S., "A Concept of Operations for a NextGen Metroplex Scheduling Concept," Eleventh AIAA Aviation, Technology, Integration, and Operations (ATIO) Conference, AIAA-2011-7065, Virginia Beach, VA, September 2011

${ }^{10}$ Long, D., Hart, G., and Hasan, S., "Initial Benefits Assessment of System Oriented Runway Management," Eleventh AIAA Aviation, Technology, Integration, and Operations (ATIO) Conference, AIAA 2011-6923,Virginia Beach, VA, September 2011

${ }^{11}$ Federal Aviation Administration Operations and Performance Data website (https://aspm.faa.gov/Default.asp), cited February $1,2013$. 
${ }^{12}$ Cheng, F., Gulding, J., Baszczewski, B., and Galaviz, R., “An Optimization-Based Sample Day Selection Algorithm for Future Schedule Generation," Eleventh AIAA Aviation, Technology, Integration, and Operations (ATIO) Conference, AIAA 2011-7054, Virginia Beach, VA, September 2011 